\title{
Digital natives and digital immigrants revisited: a case of CALL
}

\author{
Maria Zenios and Eleni Ioannou \\ UCLan Cyprus \\ mzenioul@uclan.ac.uk
}

\begin{abstract}
The aim of the paper is to examine the uses of CALL among students and teachers in Cyprus private secondary education. The notions of digital native and digital immigrant are revisited as part of the framework set for understanding the current situation in CALL exploitation and future potential within and beyond the classroom walls. A survey investigation is conducted for the collection of the data. Results indicate that a third category of users emerges, the 'inbetweeners' who may have a key role to play in CALL integration.
\end{abstract}

Keywords: digital natives, digital immigrants, CALL.

\section{Introduction}

Computer-assisted language learning (CALL) has developed over the recent years into an integral part of the classroom and teaching methodology. The European Union directives encourage CALL as a development of multilingualism and see it as a platform for the development of global trade and market. This is a result of CALL's impact on the ability to learn languages often through international exposure. Through CALL, the teacher and the learner have access to material beyond their own borders and traditions, engage into a globalized culture that may potentially respect for languages and traditions, and access plausible educational strategies that can be adopted and adjusted to satisfy their own range needs and abilities.

In the 1960's, CALL was termed as a language learning and teaching approach which used a computer as a tool for presenting and evaluating materials, assisting students and promoting interaction [1]. In its early steps, CALL research was oriented into the evaluation of the uses of emerging computer learning programmes that opted for computer-learner interaction through the provision of materials, learning activities and personalized feedback. Recent trends in CALL argue for a much learner oriented approach that favours social and situated learning approaches that promote interactivity and collaboration between learners and tutors. Recent research [18] indicates that language learning has also been affected by social sedia. Web 2.0 uses have favoured the development of an autonomous learner where the effect of the teacher in the classroom is lessening. Lee [8] suggests that blogging and podcasting enhance digital literacy and 
participation, including online content creation and sharing, thus, leading to the conclusion that language learning is reinforced via online collaborative tools. Such developments point to a pressing need to identify the level of technical skills acquired by secondary school students and their tutors in order to help the teaching community take important educational design decisions over the appropriateness of available tools to use for collaborative purposes in the classroom.

The aim of the study is to examine the place of CALL in the Cypriot private educational sector with emphasis in collaborative learning. As part of this agenda one needs to revisit the terms 'digital native' and 'digital immigrant' initiated by Prensky [10-13] in order to identify the extent to which this gap still exists at the age of constant technological development. It is clear that we have a continuous improvement of the user experience to the extent that the use of collaborative platforms and tools becomes fully transparent and internalized so that one does not have to worry about technical issues. Therefore, one should expect that the gap could possibly exist to a lesser extent and not be an issue in CALL integration because of teachers' readiness to implement technology. These developments point to the need to investigate whether there is a still a gap between digital natives and digital immigrants that hinders them from working collaboratively online.

\section{Theoretical Framework}

\subsection{The digital native- digital immigrant divide}

The notions of 'digital native' and 'digital immigrant' are defined as people born into the technological era, meaning from 1980 and onwards, in comparison to people born before, who had to learn to adjust to technology, respectively [12]. The digital gap has created a divide where the digital natives have overtaken the digital immigrants in their ability of technological use, leaving the non-technological generation behind in confusion as to how to proceed in this rapid social growth. Critique on Prensky [15] has resulted in further refinement of the term digital natives to include three sub-categories. Digital natives are grouped as the 'avoiders', who despite being born a digital native, do not feel the need for dependence on technological devices and so keep their use to a minimum, the 'minimalists' who make use of the trends, but not as frequently and the 'enthusiastic participants', who make full use of what the Digital Age has to offer. A digital native typically favors easily accessible multimedia sources, multitasking, usage of visual and audio tools prior to the text, spontaneous access to multimedia, is familiar with pairs work or group work and are driven by immediate rewards and personal interest.

Traditional theorists in education and curriculum design such as Vygotsky have argued on the value of student collaboration and tool mediation in learning. Although such theories seem to accommodate qualities gained from the affordances of new technologies there is still a long way to go in evolving the educational system as to adapt its curriculum and practices in as to fully exploit new technologies and CALL in particular. 
Kivunja [17] claims that children in the digital age can learn from the internet accessible sensory-rich information spaces outside the boundaries of school. Although such statements may cause concern to educationalists who see the processes of learning being beyond the mere access to powerful technologically enhanced environments, one cannot underestimate the value of multi-media stimuli in second language learning. For example, digital natives have more access and exposure to the English language through digital online gaming, for example World of Warcraft or Second Life, and Web 2.0 collaborative arrangements such as Facebook, Twitter or Viber, in which interaction with multinational people cause users to use the English language as a common means for communication purposes. Information processing in these settings is expected to differ in the new generation in comparison to the Digital Immigrant [15].

One however should pay attention to the fact that the birth of Digital Age may vary from country to country due to varied economic progression and ability and willingness to adapt to the Digital Age. Cyprus's Digital Age saw its birth in the 90's. As such, the majority if not all of the Cypriot teachers fall into the category of the digital immigrant or sit at the boundaries. Digital immigrant teachers prefer slow and controlled information, limited tasking, tend to provide a text first, give information chronologically and are expected to teach themes under the examination through the curriculum and standard testing [16]. They have an immigrant technological accent, and speak DSL (Digital as a Foreign Language), they are print centered and for them the syntax and idioms of online research can remain a foreign language [16]. As such, teachers clustered as digital immigrants find it difficult to possess fluency in this area due to previous traditions. However, as new and younger generation teachers from the digital native spectrum enter the classrooms, we see a gradual decrease of the old practices. Similarly, the 'digital divide'[19] is becoming shorter as years progress due to technologies being made more accessible, transparent and flexible.

\subsection{CALL implementation}

Recent research suggest appropriate operation of CALL in education relies on computer availability, experience, the nature of the academic courses and frequency of computer use [2]. Beyond the use of computers, students have easier access to the internet through devices such as i-pads, cell phones, and laptops. As reliance on technology is part of the digital native's life-style, the rhetoric for the employment of CALL in learning comes to the fore. Therefore, it is easy to see the possibility of the students being more inclined to learn through technology, and find motivation in the classroom environment which caters for such uses e.g. through Social Networking Sites for Language Learning (SNSLL) [17].

Most schools have preserved the traditional method of teaching, and have minimally implicated the use of technological devices, whereas a few schools have begun to rely heavily on technology in the class, as they find it a more constructive means of teaching. Prensky, [12] believes that most of the effective learning is done 'after school' when the students have liberal and independent use of their applications, and it is done at their own leisure without the heavy burdens of the institutional classroom. Hence, the term 'flipped classroom' emerges [3]. Kivunja [7] goes on to make a connection between the 
fact that some students desert school and the current model of education that was designed for the Industrial Age; it revolved around the teacher who delivered one-sizefits-all, one way lectures. Rikhye, Cook and Berge [14] believe that the language gap between the natives and immigrants needs to be closed, or at least narrowed, otherwise teaching efforts could be less effective. Surely, education is not keeping at pace with the technological-driven societal change and as a result there is a risk of alienating learners by failing to appropriately integrate ICT's into education. Therefore educators must change their teaching methodology to cater for the technologically inclined generation.

The availability of technology is one of the main factors one must be concerned with when incorporating technology into education, as mentioned previously. Another key factor is educators' preparedness to use ICT. Teachers' Professional Development plays a key role in ICT integration [17] which may link to initiatives such as cooperation within school teams, peer review mechanisms and enhancement of professional learning communities and human resources models.

Based on this framework, this study investigates whether there is a division between teachers and students in their use of technology that links back to the gap between the digital native and the digital immigrant. The following questions will be answered:

1. Does the division restrict the educator in their use of CALL?

2. To what extent do students use the technology as part of language learning? The rest of the paper sets out the research methodology followed to answer these questions and presents the results followed by discussion.

\section{$3 \quad$ Methodology}

A survey study design is adopted which is conducted in the context of the Cypriot private education sector. A pragmatist paradigm approach and a realist standpoint is followed in terms of research methodology that uses the quantitative approach, administering two distinct questionnaires, one for the students and the other for the teachers. Ethical protocols and guidelines have been followed to safeguard the interests of participants.

The settings in which participants studied and worked were not run by the Cypriot Ministry of Education and Culture, as they stand at the Private sector. Students in these schools come from English private primary schools and Cypriot primary schools and then are merged at Year 2 (having covered the same curriculum in English). It is not assumed that all students in these private schools come from high or middle socioeconomic status due to the particularities of the country and the educational system which is mostly oriented to the Greek speaking society. The mono-cultural and monolingual nature of public education is evidenced by research [9].

The private sector in Cyprus is an appropriate setting for a CALL investigation as both students and teachers are faced with a huge demand to improve their own language skills, being to a larger extent non-native English speakers and placed into a multicultural and multi-lingual setting. 


\subsection{Sampling}

The participants were comprised of 151 lower and upper school students from the ages of 11-18 and 40 teachers, ranging from senior management to teaching staff. The age range of the teacher participants were 20-50. A broader scope of data were collected to ensure accuracy in findings.

The teachers group comprised of all specialties, not English teachers only because the study is interested to see their own use of CALL. Yet, twenty five out of forty are teachers of English. Two questionnaires were administered to students and teachers respectively. Therefore the trend and impact of CALL was understood from two different perspectives. Numeric descriptions of trends and opinions allowed us to make some generalisations to a certain extent [5], although limitations exist due to the small sample.

\subsection{Data analysis}

The student and teacher questionnaires were separated and each analyzed separately. Results were applied to an Excel spreadsheet and bar charts were created for the closed questions and pie charts for the questions where there was more than one option for the answer. By doing this, the bar chart allowed for comparison of the results, and the pie charts allowed for the multiple answers to be clearly sectioned. Due to the research focus she questions used in both questionnaires, were connected so as to be able to distinguish the use of CALL as a tool for education in the classroom, but also as a tool for autonomous learning and specifically, learning a language.

\section{$4 \quad$ Results}

The results of the study are structured around the three key questions under exploration, i.e. a)does a division exist between teachers and students in using CALL, b) whether the gap places any constraints in teachers using CALL and c) the extent to which students use technologies as part of language learning.

\subsection{Is there a division between teachers and students in their use of CALL, creating a gap between the digital native and the digital immigrant?}

Through this study, it was found that only $33 \%$ were considered themselves as Digital natives, $3 \%$ considered themselves to be Digital immigrants, and the majority (64\%) felt that they belonged somewhere in between (see figure 1). 


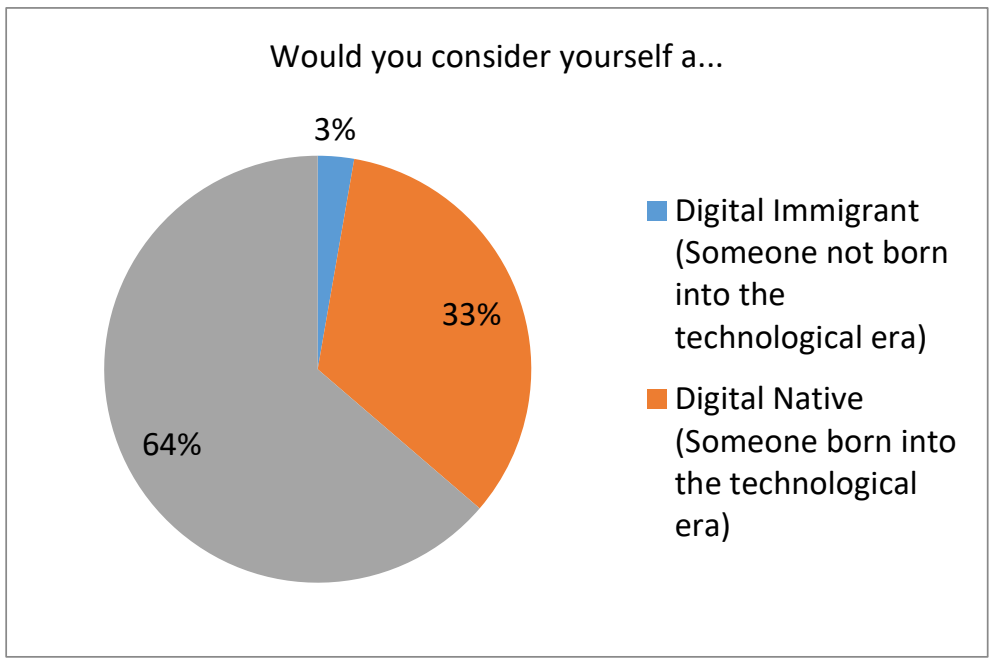

Fig. 1. Classification of students as digital natives/ immigrants

The teachers' response had a more predictable result, 32\% thought themselves to be Digital immigrants, $28 \%$ to be Digital Natives, and $40 \%$ were considered to stand somewhere in between the period of the two eras (see figure 2).

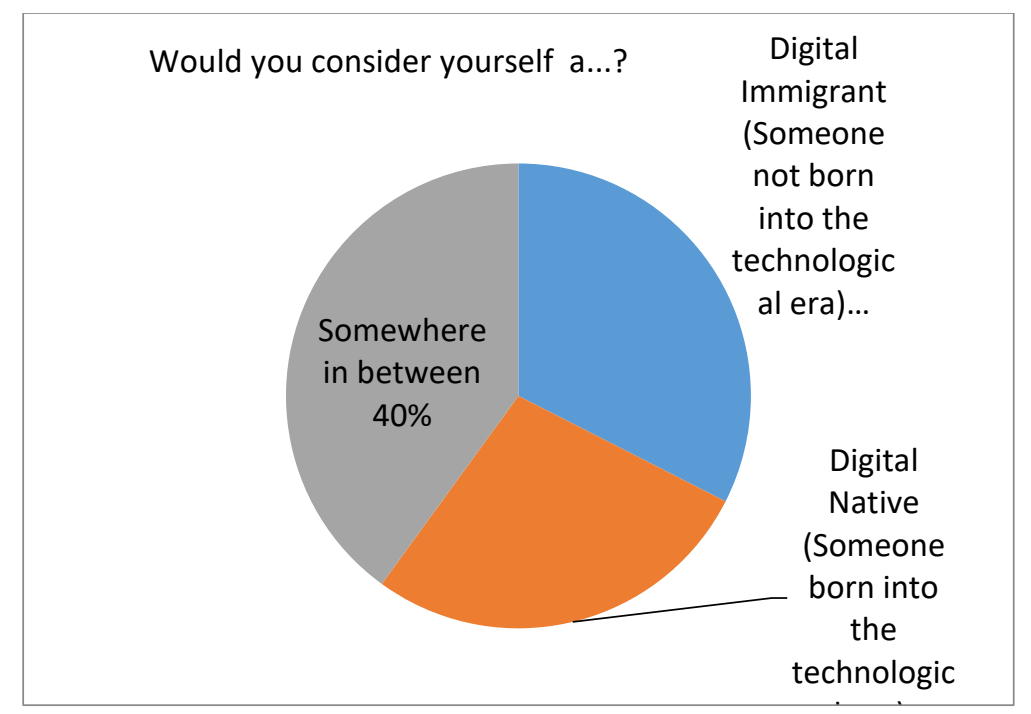

Fig. 2. Classification of school teachers as digital natives/ immigrants

The students felt that there was a digital gap between them and their teachers. Their response was that, out of the 151 students, 104 felt that the gap existed and 47 felt that 
it did not. It is important to note that the teachers' ages do play a significant role as to whether they have technological ability. The vast majority, at $53 \%$, of the teachers ages ranged from 31-40 years old, 27\% ranged from 20-30 years old, 15\% were 41-50 years old, and a the lowest percentage belonged to the ages of 51 years old and up at $5 \%$. This goes to justify as to why less than half of the students felt that there was barely a digital divide between them and the teachers.

Additionally, the teachers admitted to finding age a factor in technological progression, when 35 out of the 40 participants agreed that age is a contributing factor in the willingness to learn new technology. Evidence indicates that students are aware of the fact that they know more about technology than their teachers and they are often asked to help them in class with technical matters.

The division between the teachers and students in their use of technology is also defined by whether the two different participating groups had access to a computer at a young age and when they had started computer lessons. This determines the users' ability and familiarity with technology, seeing as the digital native, or even the participant who felt that they were somewhere in between, would have had exposure to technology at a younger age. When the students were asked whether they had computer knowledge before beginning computer classes, 135 replied positively, and only 16 replied negatively. Continuing, the students were asked how many computers they had at home, where it was clear that the majority had approximately 2 or 3 , and when further inquiring as to what age the students and the teachers had acquired their first computer, the difference was notable, where the majority of teachers had their own computer at the age of 20-21, most of the students had theirs at the age of 10 and 12. It is extremely important to note how this would affect the digital divide between digital natives and digital immigrants. Despite the availability of computers and freely available collaborative arrangements such as popular social media sites, it is clear that teachers do not encourage homework in this manner, for reasons that will be addressed further on. The use of technology by the students during the school hours or after school for their homework (see figure 3 ) is not necessarily high in comparison to the amount of time they spend on social media, as seen previously. 


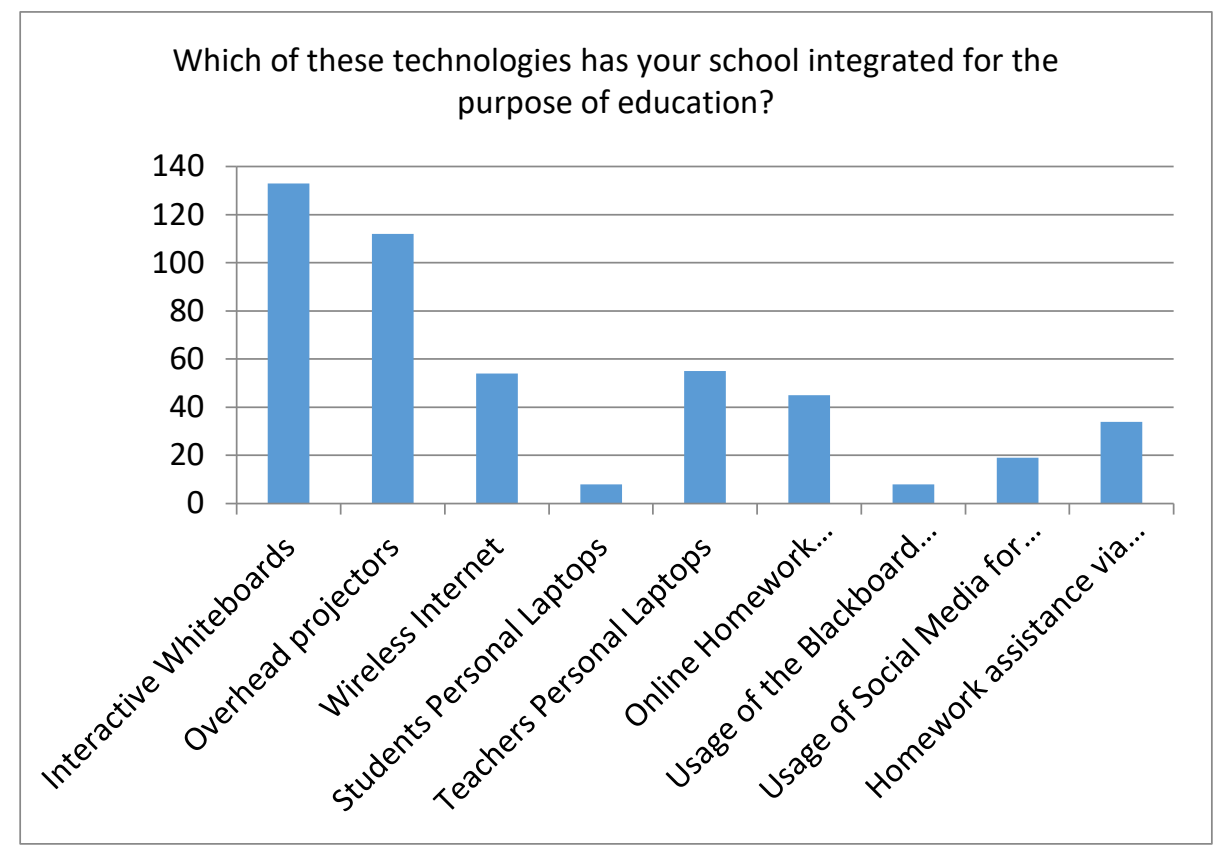

Fig. 3. Technology offered by school for students

So it is clear that the division remains between the student and the teacher and it impacts on students not being encouraged to use a diverse number of technological materials to advance their knowledge. Although this issue is influenced by many external factors, such as whether the school has the available tools for such lessons to be carried out, the students' majority $(80 \%)$ do agree that more technology should be used in the class as a means of education. This study was conducted for the purpose of seeing whether the digital divide between generations affected education and the use of CALL, specifically in the field of private education. The digital divide is not to be underestimated in terms of its expected impact in education, as communication structures, stimuli perception and internalized activity becoming part of the learning processes of the digital natives who are surrounded by media are thought to be different from those of previous generations clustered as digital immigrants.

Surprisingly, the results indicate that the majority of students did not feel that they were digital natives, $64 \%$ of them felt that they were somewhere in between a digital native and a digital immigrant, and $3 \%$ felt that they were digital immigrants. The latter can be explained by the fact that Cyprus saw a technological boost during the last 15 years, and it lacks the core industries for such progress, therefore it is reasonable to assume that the students do not feel that they can be defined as solely digital natives, when comparing themselves to other countries. The teachers were more inclined to call themselves digital immigrants seeing as they felt that they were not born into an era of such technological development. It should be recognized that despite their lack of exposure at an early age, the educators have progressed in their use of CALL, in using 
such equipment as an interactive whiteboard, or a projector, as well as the use of Social media for personal use and educational purposes to a lesser extent. Nevertheless, the generation gap was prominent through the understanding that students are more knowledgeable than their teachers and often provide assistance in class. The latter is mirrored by earlier research following a survey of 3.000 public school students that identifies a 'digital disconnect' between students and their schools due to inability to shift teaching as a response to new ways of communication beyond classroom [6].

The use of CALL is affected by a number of external factors. One of them is the upgrading of technology as well as being trained for it. This study has shown that there has been a growing need for technology to be implemented in classrooms; however, it was perceived that the majority of teachers believe that neither the private schools (whose funding comes solely from the parents association and the alumni) nor the public government funded schools are offering investments needed for sufficient upgrades.

\subsection{Does the division restrict the educator in the use of CALL?}

This question addresses the impact of the perceived technology gap in teachers' uses of technology and CALL integration in the classroom as well as their own needs in terms of language learning as they work in an English speaking multicultural setting. The division in most cases as seen through this study is understood more by the students than the teachers. However, the research shows that although the teachers feel that they can keep up with the advancement of technology, they still feel that the students are more aware of their technological surroundings than they are. Teachers' use of social media for educational purposes shows a slightly different picture with 30 teachers out of 40 having them as part of class work, extended support and homework. So it can be assumed that the perceived gap places some constraints in adopting technologies and CALL. The latter is also evidenced by our research as 22 out of the 40 teachers felt that their teaching relied heavily on technology, whereas 18 teachers said that it didn't.

Traditional methods of teaching are mostly used although the majority of educators still do believe that there has been a technological boost in education. In the case of CALL in particular, teachers' responses indicate that they had benefitted from computers in their own language learning with 27 out of the 40 confirming that in our study.

The teachers in this research believe that they are using the material provided to them to the best of their abilities, time allowing; $25 \%$ state that they always use technology in the class, whereas the majority at $43 \%$ often does. The results have shown that the educators $(45 \%)$ do spend time on the World Wide Web, searching for teaching material.

The results of this study indicate that intimidation is a factor that creates a restriction in the use of CALL by the teachers. Twenty-five out 40 participants, feel intimidated by the knowledge that their students have about technology in comparison to their own. Although they acknowledge the advantages of implementing CALL in their lessons, they are limited by the lack of confidence in their own knowledge of technology. Therefore the classroom remains primarily teacher centered; however, where implementation of CALL exists, that dominance can be shifted to a more student centered classroom. This has benefits as to learning styles adopted and materials used for comprehension, 
yet the fact that there is such a rapid influx of technology has also changed the traditional method of teaching with which the educator was comfortable with. It has overtaken the knowledge of the teacher and shifted the dynamics towards the students. This can be daunting to the teacher, and threatening towards their own dynamics in the classroom, in a sense making them feel obsolete. However, teachers still have a tremendous potential to affect the inner beliefs and values of the students, therefore they merely have to adjust their pedagogical models to suit emerging types of digital learners [4].

Through the research, it was found that although the educators are trying to keep up with technology, and allowing for change in their teaching methods, the majority are still cautious in its use because of the constant development of new programs and software. This was prominent when asked what software the teachers mostly used, where they mentioned using the basic programs such as word, power point, excel, publisher, and photo shop. It was clear that there was no attempt to further evolve into other types of programs. Thus, such understandings point to the pressing need of more training of the staff in CALL technologies so as to create an environment where the educator feels just as safe and self-assured in the use of technology as does the student.

\subsection{To what extend to students use technologies as part of language learning?}

Language learning has been a controversial subject in education, due to its nature and various approaches to it that have emerged over the years. Traditionally, English had been taught using various methods such as the grammar translation method, or learn by repetition; however, with the implementation of CALL and technology in general, language learning has progressed to encounters with culture and tradition of the country not just the language. Through this study, it was found that learning English was accomplished, not just through classes, but through computer gaming and social media. English being the official language of business and commerce, is widely used in technology.

The student questionnaire used in the study addressed learning through gaming because this requires knowledge of the English language. Findings confirm that $60 \%$ of the students play on line collaborative games (i.e. SKYRIM, 33\%, FIFA, 16\%, Minecraft, $15 \%$ Call of Duty, $11 \%$, GTA 5\%, Sims 4\%) and Friv 18\%; the latter corresponds to year 8 students and one player can play at a time). The majority of hours spent on gaming ranged from 1-3 hours (48\%), 3-6 hours (9\%) and 6+ hours (9\%).

Students have stated that their English language learning has been improved through the use of the aforementioned networks, in fact $57 \%$ believe that computer gaming has helped them in their education, and $68 \%$ believe that technology has helped them to improve their English proficiency. Gaming may have an impact on language development as it caters for the creation of online communities, in which players have direct contact with the speaker, therefore, left with no choice but to speak the language. Even if the players are not English, the English language is used as a means of communication.

The uses of social media is another array which requires the use of English to a certain extent [18], with the exception perhaps of Instagram. Findings confirm that the most common account students have is Facebook at almost 140 student participants out 
of $151(93 \%)$, and then came Instagram, Snapchat, Viber, Skype, and Twitter. When it comes to using social media for educational purposes, $48 \%$ admitted to using the social media always, $36 \%$ used it often, $15 \%$ sometimes, and a mere $1 \%$ never.

The connectivity that social media allows for, has also created a wider scope of knowledge for the user, permitting for an insight into diverse cultures, beliefs and traditions, which the user could not have accessed easily and in detail by other means. Through digital tools such as Voicethread, Audioboo, Blackboard Collaborate and Blogger, it has been possible for the user to have global interaction, and experience new languages, e.g. users can learn idioms and everyday phrases that are not used in their own culture.

One hundred and eight of the 151 student participants believe that technology is now a way of life and 138 believe that it has made life simpler. The mobile phone has allowed for constant communication, and computer gaming and social media has allowed for an international connection, allowing for other issues to rise such as respect for beliefs and cultural unions. To allow for such communication however, there had to be a 'universal' language, this language has emerged to be English.

Nevertheless, consequences of technology uses are not to be seen lightly considering issues such as cyber bullying and intimidation which have arisen frequently over the years, with the latest internet trend being the 'Blue Whale', where users are enticed into following instructions over a period of time, that will eventually lead to suicide. Such outcomes see the rise in the need for cyber control and efficient monitoring of educational usage.

\section{Discussion}

The results show that the majority of students and teachers thought that there is an existing digital divide between the digital immigrant and the digital native, and that CALL was not used sufficiently used in education, especially for collaborative activities. Despite the divide, there is evidence of continuous personal progression on behalf of the teachers to be able to bridge the gap in order to implement more collaborative CALL approaches in class. Further, the study indicates a new generation of 'somewhere inbetweeners' has arisen, that do not consider themselves digital immigrants or digital natives, but somewhere in the transition of one to another. These younger teachers have the ability to use CALL in more detail, but have not quite reached the level of a digital native's abilities. This middle group of digital 'inbetweeners' has been found to be prominent in student participants of this study too; however, this does not have to do with the age factor, but more precisely to do with exposure, background, social level, and technological availability. We suggest that the future of CALL exploitation in schools falls in the hands of the digital 'inbetweeners' who may act as change agents in learning organisations and support digital immigrants in their adoption of new technologies and CALL practices. In the same vein, they are in a position to better understand the practices of the digital natives and learn from them as part of school practices that favour collaboration and dialogue between teachers and students. 


\section{References}

1. Al-Awidi MH, Ismail AS (2014) Teachers' Perceptions of the Use of Computer Assisted Language Learning to Develop Children's Reading Skills in English as a Second Language in the United Arab Emirates. Early Childhood Educ. J. 42:29-37. doi: 10.1007/s10643-0120552-7

2. Basoz T, Cubukcu F (2013) Pre-service EFL teachers' attitudes towards Computer Assisted Language Learning (CALL). Procedia - Social and Behavioral Sciences 116:531-535. doi: 10.1016/j.sbspro.2014.01.253

3. Brame C (2013) Flipping the classroom. Vanderbilt University Centre for Teaching. https://cft.vanderbilt.edu/guides-sub-pages/flipping-the-classroom

4. Chen W, Zhou C, Tan A, Wong PSK (2013) ICT experiences and competences of pre-service teachers in the digital age. https://repository.nie.edu.sg/handle/10497/14995

5. Creswell JW (2009) Research design: Qualitative, quantitative and mixed methods approaches. SAGE. London.

6. Greenhow C, Robelia B, Hughes J, (2009) Learning, teaching, and scholarship in a digital age: Web 2.0 and classroom research, what path should we take now? Educ Researcher. 38(4):246-259. doi:10.3102/0013189X09336671

7. Kivunja C (2014) Theoretical Perspectives of how digital natives learn. International $\mathbf{J}$ Higher Educ (3) 1: 94-109. doi:10.5430/ijhe.v3n1p94

8. Lee L (2016) Autonomous learning through task-based instruction in fully online language courses. Language Learning \& Technology. 20(2):81-97. http://lt.msu.edu/issues/june2016/lee.html

9. Partasi E (2011) Experiencing multiculturalism in Greek-Cypriot primary schools. Compare: A $\mathbf{J}$ of Comparative and International Educ. 4(3): 371-386 doi: 0.1080/03057925.2010.542035

10. Prensky M (2001) Digital Natives, Digital Immigrants Part 1. On the Horizon. 9(5):16, doi:10.1108/10748120110424816

11. Prensky M (2001) Digital Natives, Digital Immigrants Part 2: Do They Really Think Differently? On the Horizon. (9)6:1-6. doi:10.1108/10748120110424843

12. M (2005) Listen to the natives, Educational Leadership 63(4) ASCD. http://www.ascd.org

13. Prensky M (2009) H. Sapiens Digital: From Digital Immigrants and Digital Natives to Digital Wisdom. Innovate: J of Online Educ. 5(3) http://nsuworks.nova.edu/innovate/vol5/iss $3 / 1$

14. Rikhye R, Cook S, Berge LZ (2009) Digital natives vs Digital immigrants: Myth or reality?, ITDL 6(2) http://www.itdl.org

15. Sheely, S (2008) Latour meets the digital natives: What do we really know. In Hello! Where are you in the landscape of educational technology? In: Proceedings ASCILITE Melbourne 2008. http://www.ascilite.org.au/conferences/melbourne08/procs/sheely.pdf

16. Toledo A. C (2007) Digital Culture: Immigrants and Tourists Responding to the Natives' Drumbeat. International J Teaching and Learning in Higher Educ. 19(1):84-92. http://www.isetl.org

17. Twining P, Raffaghelli J, Albion P, Knezek D (2013) Moving education into the digital age: the contribution of teachers' professional development. J Comp Assisted Learning. 29:1-12. doi: $10.1111 /$ jcal.12031.

18. Valencia AJ (2016) Social Networking Sites for Language Learning: Examining Learning Theories in Nested Semiotic Spaces. Signo y Pensamiento 68 Avances. xxxv:66-84 doi: 10.11144/Javeriana.syp35-68.snsl 
19. Wang E, Myers DM, Sundaram D (2012) Digital natives and digital immigrants: Towards a model of digital fluency, In: ECIS 2012 Proceedings. Paper 39. http://aisel.aisnet.org/ecis2012/39 